\title{
THE EFFECT OF SMARTPHONE ADDICTION ON SLEEP QUALITY IN YOUNG PEOPLE
}

\author{
Gülsüm GÜNDOĞDU, Phd, RN, Gülsün AYRAN, PhD, RN, \\ Nurten ARSLAN IŞIK, Phd, RN \\ Faculty of Health Sciences, Erzincan Binali Yıldırım University, Erzincan, Turkey
}

\begin{abstract}
Aim: This study was conducted to determine the effect of smartphone addiction on sleep quality in young people.

Materials and Methods: The data of this descriptive study were collected from young people who visited internet cafes in Erzincan city center between February and April 2018. The Questionnaire Form, Smartphone Addiction Scale-Short Version (SAS-SV), and Pittsburgh Sleep Quality Index (PSQI) were used to collect the study data.

Results: The mean age of the young people was 21.49 , with a minimum age of 18.00 and a maximum age of 28.00. The mean duration of smartphone
\end{abstract}

use was 5.51, the mean total score of the PSQI was 6.78 , and the mean score of smartphone addiction was 28.11. A statistically significant positive and weak correlation was determined between the Smartphone Addiction Scale score and the PSQI total score and the sub-dimensions of subjective sleep quality (component 1), habitual sleep efficiency (component 4), sleep disturbances (component 5) and daytime dysfunction (component 7) $(\mathrm{p}<0.050)$.

Conclusion: It was determined that as the duration of smartphone use increased, smartphone use addiction increased and the sleep quality of young people deteriorated.

Keywords: Smartphone, Addiction, Young Person, Sleep Quality.

\section{INTRODUCTION}

According to the diagnosis in the Diagnostic and Statistical Manual of Mental Disorders (DSM-V), an addicted individual feels an irresistible desire for the addictive substance, regardless of time and place, spends a lot of time in activities necessary to use the substance, is unable to quit the substance despite many attempts to quit, uses increasing doses of the substance, experiences withdrawal symptoms in the absence of the substance, and continues to use the substance despite experiencing permanent or recurrent physical and psychological problems and deterioration in social and occupational activities due to substance use. Addiction, which is also defined as a faulty will disease that occurs as a result of cognitive impairment, can be based on a physical substance such as cigarettes, alcohol, drugs, or it can be based on behavior such as games and smartphones [1,2].

* Corresponding Author: Asst. Prof. Nurten ARSLAN ISIK, PhD, Msc, RN, Erzincan Binali Yildirim University Faculty of Health Sciences Mental Health and Psychiatric Nursing Department, mobil: 00905055273641 email: nurtenarslanisik1@gmail.com

Article received: 30.09 .2021 , accepted: 15.10 .2021 , published: 20.10 .2021

Cite: Gündoğdu G, Ayran G, Arslan Isik N. The effect of smartphone addiction on sleep quality in young people. The Journal of School and University Medicine 2021;VIII(3): 5-13 
Smartphones, which are one of the most important tools that contribute to the transformation and popularity of technology, are becoming an indispensable element for individuals due to the fact that they meet both functional and emotional needs such as being able to follow up on work, receiving and sending e-mails, shopping, messaging, video calling, following social networks, playing games, listening to music, watching movies or TV series $[1,3]$. According to the data for 2019, more than 1.5 billion people in the world use smartphones [4]. As Akman points out, according to Digital in 2018 in Western Asia Report, while the rate of mobile phone use in Turkey is $98 \%$, the rate of smartphone use is $77 \%$ [5]. According to the 2019 data of the Household Information Technologies Usage Survey of the Turkish Statistical Institute, the rate of having a mobile phone/smartphone in households is $98.7 \%$, and the rate of internet use is $75.3 \%$ between the ages of $16-74$, while this rate is explained as $90.8 \%$ for individuals between the ages of 16-24 [6].

Factors such as emotional problems, the need for socialization and the search for identity may make adolescents and young people more susceptible to technological addictions such as mobile phone addiction/smartphone addiction. Although smartphone addiction, also known as problematic mobile phone use, is not defined in the DSM-V, it is considered a type of non-chemical behavioral addiction associated with the consequences of obsessive phone use, including human-machine interaction, as a concept related to psychopathology, constantly checking messages or updates, tolerance for longer and more intense use, feeling of suffering in the absence of phone, impairment in other life activities and social relations. Since smartphone addiction has many aspects similar to internet addiction, internet addiction criteria are taken into account while developing mobile phone addiction/smartphone addiction criteria $[7,8,9]$.

Smartphone/internet addiction causes many physical and psychological problems such as head, neck, back and shoulder pain, numbness and pain in the hands and wrists, dizziness, eye strain and vision problems, carpal tunnel syndrome, repetitive motion injuries, stomach pain, $[7,10]$ attention deficit, eating disorder, anger, panic attack, personality and mood disorders, $[1,8]$ weakening of patience and tolerance, resorting to violence in problem solving, atrophying of the sense of pity, banality of evil, epileptic seizures and depression [3]. Furthermore, it causes many fears and phobias such as fear of losing the smartphone, forgetting it at home/work (nomophobia), [11] fear of missing out (FOMO), fear of being unable to access the internet (netlessphobia), fear of running out of battery (plugomania) and sociotelism in individuals addicted to smartphones, which negatively affect the individual's school, work or private life, reduce the communication of individuals with other individuals in their social environment and make them insensitive to events around them $[1,7,8,9,11]$.

Technology addiction/smartphone addiction, which makes adolescents more sensitive due to factors such as emotional problems, the need for socialization, and the search for identity, brings along sleep problems $[7,8,9]$. It is stated that the blue light emitted from smartphones affects melatonin levels, the use of smartphones at night and exposure to electromagnetic fields affect brain activity, especially the pineal gland, and cause changes in cerebral blood flow and brain electrical activity, resulting in a decrease in sleep quality [7,9]. In studies investigating the effect of smartphone use on sleep quality in adolescents and young people, it was stated that smartphone use directly affected sleep quality, that there was a correlation between smartphone addictions and sleep quality, and the higher the smartphone addiction was, the lower the sleep quality was. This study was conducted to determine the effect of smartphone addiction on sleep quality in young people $[12,13,14,15,16,17,18$ $, 9,20,21,22,23,24,25,26,27,28,29]$.

\section{MATERIALS AND METHODS}

\section{Type of the Study}

The study was conducted as a descriptive study to determine the effect of smartphone addiction on sleep quality in young people.

\section{Place and Time of the Study}

The study data were collected from young people who visited internet cafes in Erzincan city center between February and April 2018. 


\section{Population and Sample of the Study}

The population of this study consists of young people in the province of Erzincan. The sample consisted of young people who visited internet cafes in Erzincan city center and agreed to participate in the study.

\section{Data Collection Tools}

The Questionnaire Form, Smartphone Addiction Scale-Short Version (SAS-SV), and Pittsburgh Sleep Quality Index (PSQI) were used to collect the study data.

Questionnaire Form: The questionnaire form, which was prepared by the researchers in line with the literature, consists of questions aimed at determining some socio-demographic characteristics, internet use and sleep status of young people.

Smartphone Addiction Scale-Short Version (SAS-SV): The Smartphone Addiction Scale-Short Version (SAS-SV) is a 10-item, single-factor, and six-point Likert-type scale developed by Kwon et al. to measure the risk of smartphone addiction in adolescents. In the scale consisting of ten questions, each item is scored from one to six, and the scale scores range from 10 to 60 . The higher the score obtained from the test is, the higher the addiction is. In their study, Kwon et al. determined the cut-off score as 31 points for males and 33 points for females. Cronbach's alpha coefficient was measured as 0.91 in the study of Kwon et al. and 0.87 in the study of Noyan et al., which was adapted into Turkish [30,31].

Pittsburgh Sleep Quality Index (PSQI): The Pittsburgh Sleep Quality Index is a scale developed by Buysse et al. in 1989 to evaluate the sleep quality of patients in clinical studies. The validity and reliability studies of this scale in our country were carried out by Ağargün et al. in 1996. Cronbach's alpha reliability coefficient of the scale was found to be 0.80 . The PSQI evaluates sleep quality in the last month. Nineteen questions in the PSQI, which includes a total of 24 questions, are answered by the individual himself/herself, and five questions are answered by the spouse or a roommate. Five questions answered by the individual's spouse or a roommate are used for clinical information and are not included in the scoring. The 19th question in the scale questions whether there is a spouse or a roommate, and the answer to this question is not included in the calculation of the PSQI total and component scores. The first 18 questions answered by the individual are used to calculate the PSQI total and component scores. The 18 questions included in the scoring are divided into 7 components. Each component is evaluated over 0-3 points. The PSQI total score is obtained by summing the seven component scores. The total score has a value between 0 and 21 points. A high total score indicates poor sleep quality of the individual. A PSQI total score greater than 5 was accepted as the cut-off score indicating poor sleep quality. The PSQI components include subjective sleep quality (component 1), sleep latency (component 2), sleep duration (component 3), habitual sleep efficiency (component 4), sleep disturbances (component 5), use of sleeping medications (component 6), and daytime dysfunction (component 7). In component 1 , it is questioned how the sleep quality has been in the last month in general. In component 2 , the duration of falling asleep at night in the last month and whether there is a problem of not being able to fall asleep within 30 minutes and its frequency are questioned. In component 3 , it is questioned how many hours the individual has slept at night in the last month. In component 4 , it is questioned what time the individual has gone to bed at night, what time he/she has woken up in the morning, and how many hours he/she has slept at night in the last month. In component 5 , the presence and frequency of waking up in the middle of the night or early in the morning, having to get up to go to bathroom, not being able to breathe easily, coughing or snoring loudly, feeling extremely cold, feeling extremely hot, having bad dreams, pain and other causes are questioned. In component 6 , it is questioned how often sleeping medications have been taken to aid sleep in the last month. In component 7, it is questioned how often the individual has had difficulty staying awake while driving, eating, or during social activities in the last month, and to what extent this prevented him/her from doing his/her work with enough enthusiasm [32].

\section{Ethical Principles of the Study}

Permission was obtained from the relevant institution to conduct the study. After the young people who participated in the study were informed about the study, they were informed that they were free to 
participate in the study and to leave the study whenever they wanted and that their personal information would not be used anywhere other than this study.

\section{Data Collection}

A questionnaire form with open-ended questions, the Smartphone Addiction Scale-Short Version, and the Pittsburgh Sleep Quality Index were used as data collection methods in the study. The study data were collected face to face with the survey method.

\section{Analysis and Evaluation of Data}

The data were analyzed using IBM SPSS V23. Percentage, mean and Spearman's rho correlation coefficient were used in the evaluation of the data. A statistical significance level was accepted as $p<0.05$ in all tests.

\section{Limitations of the Study}

The study results are limited to the young people who visited the cafes where the data were collected during the data collection dates and participated in the study. In the study, the sleep quality of the young people is limited to the structures in the Pittsburgh Sleep Quality Index, and their internet use is limited to the structures in the Smartphone Addiction Scale-Short Version (SAS-SV).

\section{RESULTS}

In Table 1, it was determined that $77.8 \%$ of the participants were male, $38.3 \%$ were connected to the internet between 4-6 hours, $79.8 \%$ used a phone in bed, and $54.4 \%$ had a change in sleep duration.

\begin{tabular}{|c|c|c|}
\hline & $\mathrm{n}$ & $\%$ \\
\hline \multicolumn{3}{|l|}{ Sex } \\
\hline Female & 55 & 22.2 \\
\hline Male & 193 & 77.8 \\
\hline \multicolumn{3}{|c|}{ Internet connection } \\
\hline less than 1 hour & 19 & 7.6 \\
\hline 1-3 hours & 86 & 34.7 \\
\hline 4-6 hours & 95 & 38.3 \\
\hline more than 7 hours & 48 & 19.4 \\
\hline \multicolumn{3}{|c|}{ Using a smartphone in bed } \\
\hline Yes & 198 & 79.8 \\
\hline No & 50 & 20.2 \\
\hline \multicolumn{3}{|c|}{ Is there a change in bedtime? } \\
\hline Yes & 135 & 54.4 \\
\hline No & 83 & 33.5 \\
\hline No idea & 30 & 12.1 \\
\hline
\end{tabular}

Table 1: Descriptive statistics of the quantitative data $(N=248)$

In Table 2, the mean age of the participants was 21.49 , with a minimum age of 18.00 and a maximum age of 28.00. The mean duration of smartphone use was 5.51 , the minimum duration was 2 , and the maximum duration was 12 . The mean PSQI total score was 6.78 , and the mean smartphone addiction was 28.11 . 
Research article

\begin{tabular}{lccccc}
\hline & $\mathbf{X}$ & $\mathbf{S S}$ & $\mathbf{X}_{\text {ort }}$ & Min & Max \\
\hline Age & 21.49 & 2.17 & 22.00 & 18.00 & 28.00 \\
\hline Smartphone usage time & 5.51 & 2.25 & 5.00 & 1.00 & 12.00 \\
\hline Subjective sleep quality & 1.06 & 0.87 & 1.00 & 0.00 & 3.00 \\
\hline Sleep latency & 1.21 & 0.96 & 1.00 & 0.00 & 3.00 \\
\hline Sleep time & 1.50 & 0.88 & 2.00 & 0.00 & 3.00 \\
\hline Habitual sleep activity & 0.71 & 1.02 & 0.00 & 0.00 & 3.00 \\
\hline Sleeping disorder & 0.95 & 0.22 & 1.00 & 0.00 & 1.00 \\
\hline Use of sleeping pills & 0.34 & 0.69 & 0.00 & 0.00 & 3.00 \\
\hline Daytime sleep dysfunction & 1.01 & 0.85 & 1.00 & 0.00 & 3.00 \\
\hline PSQI total & 6.78 & 3.07 & 7.00 & 0.00 & 17.00 \\
\hline & & & & & \\
Smartphone Addiction Scale & 28.11 & 10.94 & 28.00 & 10.00 & 57.00 \\
\hline
\end{tabular}

Table 2: Frequency distribution of categorical variables $(N=248)$

In Table 3 , there is a statistically significant positive and weak correlation between the Smartphone Addiction Scale score and the PSQI total score and the sub-dimensions of subjective sleep quality (component 1), habitual sleep efficiency (component 4), sleep disturbances (component 5), and daytime dysfunction (component 7$)(\mathrm{p}<0.050)$.

\begin{tabular}{lcc}
\hline & \multicolumn{2}{c}{ SAS-SV } \\
Subjective sleep quality & 0.160 & $\mathbf{0 . 0 1 2}$ \\
\hline Sleep latency time & 0.116 & 0.068 \\
\hline Sleep duration & 0.117 & 0.066 \\
\hline Habitual sleep activity & 0.165 & $\mathbf{0 . 0 0 9}$ \\
\hline Sleep disturbance & 0.271 & $<\mathbf{0 . 0 0 1}$ \\
\hline Taking sleeping pills & 0.068 & 0.288 \\
\hline Sleep disturbance during the day & 0.256 & $<\mathbf{0 . 0 0 1}$ \\
\hline PSQI total & 0.248 & $<\mathbf{0 . 0 0 1}$ \\
\hline
\end{tabular}

Table 3: The Relationship Between SAS And PSQI

\section{DISCUSSION}

The results of this study, which was conducted to determine the effect of smartphone addiction on the sleep quality of young people, were discussed in line with the literature. It was determined that $38.3 \%$ of the young people in our study were connected to the internet between 4-6 hours a day. In the study conducted by Haug et al. to determine smartphone use and smartphone addiction in young people in Switzerland, it was determined that $42.8 \%$ of young people had a duration of smartphone use between 3-6 hours a day. In the study carried out by Bulduklu and Özer to determine the smartphone use motivations of young people, it was revealed that $65.2 \%$ of them had a duration of smartphone use between 3-6 hours a day. In the study performed by Kocamaz et al. to determine the correlation between smartphone addiction, sleep quality and depression in university students, the mean duration of daily phone use was 4 hours. In the cross-sectional study carried out by Sohn et al. to determine the correlation between smartphone addiction and sleep in young adults in England, it was revealed that $60.9 \%$ of the participants had a duration of smartphone use between 3-5 hours a day [33,34,35,36]. Upon examining the studies, it was determined that the majority of the participants used smartphones between 3-6 hours a day, and our study supports these results of the literature.

It was determined that $79.8 \%$ of the young people in our study used the phone in bed and $54.4 \%$ had a change in sleep time (Table 1). In the study carried out by Yumuşak to determine smartphone addiction, sleep quality and life satisfaction in university students, it was found that $49.9 \%$ of the students used the smartphone in the evening and $27.6 \%$ at night. 
In the study conducted by Chung et al. to determine the risk of smartphone addiction and daytime sleepiness in Korean adolescents, it was revealed that $80.6 \%$ of them were in the risk group for smartphone use after twelve at night. In the cross-sectional study of Sohn et al. examining the correlation between smartphone addiction and sleep in young adults in England, it was determined that $59.9 \%$ of them used smartphones in the bedroom. In the study of Özcan examining the correlation between sleep quality and smartphone addiction in Pamukkale University students, the use of smartphones in bed was found as $89.8 \%$. Our study showed that phone use during the day continued in the evening and at night, supporting the results and the literature $[36,37,38,39]$.

In our study, the mean duration of smartphone use was determined as 5.51 (Table 2). In the study conducted by Bulduklu and Özer to determine the smartphone use motivations of young people, it was revealed that $40 \%$ of the participants had a smartphone use period of 4-5 years. In the study of Yildırım et al. examining smartphone addiction and related factors in first-grade medical faculty students of a university, it was determined that $49.1 \%$ of the students had been using a smartphone for at least 5 years. In the study of Kuyucu titled "The problem of smartphone use and smartphone addiction in youth: "Smartphoneaddicted" university youth", it was determined that $83.1 \%$ of the participants had a smartphone use period of more than 3 years. Chung et al. found that $46.8 \%$ had been using a smartphone for 3-5 years, and Öcal Üstündağ determined that $41.7 \%$ of the students had been using a smartphone for 5-6 years, with the risk of smartphone addiction in university students, its effect on sleep quality, and its correlation with mental symptoms. The mean smartphone use period of the young people in our study was found to be similar to the literature $[35,38,40,41,42]$.

In our study, the mean PSQI total score of the participants was 6.78 , and the SAS-SV was 28.11 (Table 2). In the study performed by Kocamaz et al. to determine the correlation between smartphone addiction, sleep quality and depression in university students, it was found that the mean PSQI total score was $6.97 \pm 5.28$ and the mean smartphone addiction was $31.68 \pm 10.19$. In the study of Yildirım et al. examining smartphone addiction and related factors in first-grade medical faculty students of a university, it was determined that those who perceived their smartphone addiction as yes had a mean smartphone addiction scale score of $85.8 \pm 22.4$, and those who perceived as no had a mean smartphone addiction scale score of $68.9 \pm 22.6$. In the study of Keskin et al. examining the correlation between smartphone use and headache in university students, it was revealed that the mean smartphone addiction scale score was 29.2 \pm 11.2 . In the study of Erdoğanoğlu and Arslan examining the effect of smartphone use on physical capacity in young people, it was determined that the mean smartphone addiction scale score was $33.24 \pm 8.60$ in females and $31.04 \pm 10.78$ in males, the mean PSQI total score of the students was $6.7 \pm 3.0$, and their mean SAS-SV score was 28.1 \pm 10.6 . In the study conducted by Yumuşak to determine smartphone addiction, sleep quality and life satisfaction in university students, it was found that the mean PSQI total score of students was $6.24 \pm 2.63$ and their mean SAS-SV score was $29.18 \pm 10.43$ [35, 40,43,44,37]. Our study supports the literature in terms of the poor sleep quality of young people and the presence of smartphone addiction.

There is a statistically significant positive and weak correlation between the SAS-SV and PSQI total score, the sub-dimensions of subjective sleep quality, habitual sleep efficiency, sleep disturbances and daytime dysfunction $(\mathrm{p}<0.050)$ (Table 3$)$.

In the study of Kocamaz et al. examining the correlation between smartphone addiction, sleep quality and depression in university students, it was determined that there was a positive and weak correlation between the SAS-SV and PSQI $(r=0.178$, $\mathrm{p}=0.036$ ). In the study of Ozkaya et al., in which the frequency of smartphone use/addiction and its effect on sleep quality in university students were evaluated, it was revealed that there was a significant correlation between smartphone addiction and sleep quality ( $r: 0.193, p=0.014)$. In the study of Çevik examining the correlation between smartphone addiction and sleep quality, depression and anxiety levels in university students, it was determined that as the smartphone addiction scale scores of students increased, their sleep quality scale scores also increased, and there was a statistically significant positive correlation between the scores students received from the 
smartphone addiction scale and the scores they received from the sleep quality scale $(r=0.245 ; \mathrm{p}<0.01)$. Öcal Üstündağ detected that there was a statistically significant positive and weak correlation between the risk of smartphone addiction, its effect on sleep quality and mental symptoms in university students, and between the scores students received from the smartphone addiction scale-short version and the scores they received from the PSQI $(\mathrm{r}: 0.237, \mathrm{p}:<0.001)$. In the study of Yumuşak, there was a statistically significant positive and weak correlation between the risk of smartphone addiction, its effect on sleep quality and life satisfaction levels in university students, and between the scores students received from the smartphone addiction scale-short version and the scores they received from the PSQI (r:0.203, p:0.001). In the study of Özcan examining the correlation between sleep quality and smartphone addiction in Pamukkale University students, it was determined that there was a positive and significant correlation between the PSQI total scores and the SAS-SV scores of the participants in the research group $(\mathrm{r}: 0.203, \mathrm{p}:<0.001)$. In the study conducted by Haripriya et al. to determine the correlation between smartphone addiction, sleep quality and physical activity among young adults, it was found that there was a moderately significant positive correlation between the SAS and PSQI scores (0.473). In the cross-sectional study conducted by Sohn et al. to determine the correlation between smartphone addiction and sleep in young adults in England, smartphone addiction was found to be associated with poor sleep $(p=0.018)[35,37,39,42,45,46,47,48]$. The result of our study supports the literature.

\section{CONCLUSION}

In our study conducted to determine the effect of smartphone addiction on sleep quality in young people, it was determined that as the use of smartphones increased, the sleep quality of young people deteriorated, the sleep quality of the young people in our study was impaired, the sleeping-waking and healthy sleep habits were negative especially in the last month, and this negatively affected their desire and success in maintaining their daily life activities and social life. To control the use of smartphones, which has become a global public health problem and causes neurocognitive changes in case of addiction, studies should be carried out in different regions to determine this addiction status in young people. Furthermore, strategies should be developed to raise awareness in order to address what kind of activities phones are used for, to control the use of smartphones and to eliminate the negative problems that may arise with its direct effect on sleep quality and disruption of sleep patterns, and young people should be encouraged to provide self-control for sleep and exercise in order to reduce addiction.

\section{REFERENCES}

1. Koca, E. B.(2019). A Literature Review on Smartphone Addiction and Sociootelism. Avrasya Sosyal ve Ekonomi Araştırmaları Dergisi, 6(6), 399-411.

2. Vaghefi, I., \& Lapointe, L. (2014, January). When too much usage is too much: Exploring the process of it addiction. In 2014 47th Hawaii International Conference on System Sciences (pp. 4494-4503). IEEE.

3. Küçükvardar, M., \& Tingöy, Ö. (2018). Examining Technology Addiction on the Basis of Symptoms. Ajtt-E: Bilişim Teknolojileri Online Dergisi, 9(35), 111-123. https://doi. org/10.5824/1309-1581.2018.5.008.x

4. Faik, İ. 1. i. k., Büyükgöl, H., Mehmet, U. y. a. r., \& Ertem, D. H. (2018). Overuse of Smartphones as a Triggering Factor for Migraine Attacks. Acıbadem Üniversitesi Sağlık Bilimleri Dergisi, (3), 447-450. https://doi.org/10.31067/0.2019.167

5. Akman, E. (2019). The Effect of Fear of Being Without a Smartphone (Nomophobia) on Academic Achievement: An Evaluation of Süleyman Demirel University Political Science and Public Administration Students. Avrasya Uluslararast Araştırmalar Dergisi, 7(16), 256-275. https://doi.org/10.33692/ avrasyad.543756

6. https://data.tuik.gov.tr/Bulten/Index?p=Survey-on-Informati on-and-Communication Technology-(ICT)-Usage-in-House holds-and-by-Individuals-2020-33679

7. Moattari, M., Moattari, F., Kaka, G., Kouchesfahani, H. M., Sadraie, S. H., \& Naghdi, M. (2017). Smartphone Addiction, Sleep Quality And Mechanism. Int J Cogn Behav, 1(002).

8. Ektiricioğlu, C., Arslantaş, H., \& Yüksel, R. (2020). Ergenlerde Çağın Hastalığı: Teknoloji Bağımlılığı. Arşiv Kaynak Tarama Dergisi, 29(1), 51-64. https://doi.org/10.17827/aktd.498947

9. Keskin, T., Ergan, M., Başkurt, F., \& Başkurt, Z. (2018). Üniversite Öğrencilerinde Akıllı Telefon Kullanımı ve Baş Ağr; Jiaxin 1sı İlişkisi. Adıyaman Üniversitesi Sağllk Bilimleri Dergisi, 4(2), 864-873. https://doi.org/10.30569/adiyamansaglik.428223 10. Çalışkan H. Taşınabilir Teknolojiler, Yüzer T.V, Okur M.R (Editörler). Temel Bilgi Teknolojileri-I. 1. Bask1, Eskişehir, Anadolu Üniversitesi Web-Ofset Tesisleri, 2015: 115-122. https://www.anadolu.edu.tr/uploads/anadolu/ckfinder/web/files/ BIL101U.pdf 
11. Şakiroğlu M, Akyol C. P.Bağlan Sorunlu akıllı telefon kullanımını azaltma rehberi, Çubukçu S. (Editörler). 1. Bask1, İstanbul, Doğan Egmont Yayıncılık ve Yapımcılık Tic. A.Ş, 2020: 1-19.

12. Liu, Q., Zhou, Z., Niu, G., \& Fan, C. (2017). Mobile phone addiction and sleep quality in adolescents: Mediation and moderation analyses. Acta Psychologica Sinica, 49(12), 1524. https:/ doi.org/10.3724/SP.J.1041.2017.01524

13. Asiyah, S. N., \& Putri, A. Y. (2018, October). Relationship between Smartphone Addictions with Sleep Quality in Adolescents. In International Conference on Sustainable Health Promotion (pp. 92-99).

14. Lee, J. E., Jang, S. I., Ju, Y. J., Kim, W., Lee, H. J., \& Park, E. C. (2017). Relationship between Mobile phone addiction and the incidence of poor and short sleep among Korean adolescents: a longitudinal study of the Korean Children \& Youth Panel Survey. Journal of Korean medical science, 32(7), 1166-1172. https://doi. org/10.3346/jkms.2017.32.7.1166

15. Shim, M., Han, G. Y., Kim, B., Kim, S. Y., Cho, S. M., Lee, K. S., . \& Choi, Y. A. (2017). Relation between smartphone usage and sleep pattern and deprivation: A survey on high school students. Korean Journal of Family Practice, 7(3), 418-423. https:// doi.org/10.21215/kjfp.2017.7.3.418

16. Kocas, F., \& Şaşmaz, T. (2018). Internet addiction increases poor sleep quality among high school students. Turkish Journal of Public Health, 16(3), 167-177. https://doi.org/10.20518/ tjph.407717

17. Kurugodiyavar, M. D., Sushma, H. R., Godbole, M., \& Nekar, M. S. (2018). Impact of smartphone use on quality of sleep among medical students. Int J Community Med Public Health, 5(1), 1019. https://dx.doi.org/10.18203/2394-6040.ijcmph20175604

18. Bunyalug, M., \& Kanchanakhan, N. (2017). Effect of Using Smartphone before Bed on Sleep Quality among Undergraduate Students at Chulalongkorn University, Thailand. Journal of Health Research, 31(Suppl. 2), S225-231.

19. Jniene, A., Errguig, L., El Hangouche, A. J., Rkain, H., Aboudrar, S., El Ftouh, M., \& Dakka, T. (2019). Perception of sleep disturbances due to bedtime use of blue light-emitting devices and its impact on habits and sleep quality among young medical students. BioMed research international, 2019. https:// doi.org/10.1155/2019/7012350

20. Gündoğmuş İ, Aydın M.B, Aydın M.S. The impact of using social network services on the smartphone addiction and sleep quality in university student. Klinik Psikofarmakoloji Bulteni. 2019; 29: 44-45.

21. Bayatiani, M. R., Seif, F., \& Bayati, A. (2016). The correlation between cell phone use and sleep quality in medical students. Iranian Journal of Medical Physics, 13(1), 8-16. https://dx.doi. org/10.22038/ijmp.2016.7140

22. Demirci, K., Akgönül, M., \& Akpinar, A. (2015). Relationship of smartphone use severity with sleep quality, depression, and anxiety in university students. Journal of behavioral addictions, 4(2), 85-92. https://doi.org/10.1556/2006.4.2015.010

23. Chiranthie, H., Ibukunoluwa, F., Hodan Idriss, A., Samantha, S., Sumya, H., Latifa, A., \& Shatha, A. S. (2014). < The > effects of electronic device use on the sleep quality of health science students in The United Arab Emirates.
24. Khan, K. W., Imran, S. S., \& Idris, S. (2017). Do Mobile Addicts have Poor Sleep Quality?. Annals of PIMS-Shaheed Zulfiqar Ali Bhutto Medical University, 13(4), 306-309.

25. Sohn, S., Rees, P., Wildridge, B., Kalk, N. J., \& Carter, B. (2019). Prevalence of problematic smartphone usage and associated mental health outcomes amongst children and young people: a systematic review, meta-analysis and GRADE of the evidence. BMC psychiatry, 19(1), 1-10. . https://doi.org/10.1186/ s12888-019-2350-x

26. Chongchitpaisan, W., Wiwatanadate, P., Narkpongphun, A., Tanprawate, S., \& Siripon, N. (2020). Sleep loss among Thai high school students smartphone users affected by smartphone electromagnetic pollution: Time series study. Journal of Health Research. Doi: 10.1108/JHR-05-2019-0104

27. Dinis, J., \& Bragança, M. (2018). Quality of sleep and depression in college students: a systematic review. Sleep Science, 11(4), 290. https://dx.doi.org/10.5935\%2F1984-0063.20180045

28. Gupta, N., Garg, S., \& Arora, K. (2016). Pattern of mobile phone usage and its effects on psychological health, sleep, and academic performance in students of a medical university. National Journal of Physiology, Pharmacy and Pharmacology, 6(2), 132139. Doi:10.5455/njppp.2016.6.0311201599

29. Mehta A, Lingeshwaran G. Changing rhythm of life- modern epidemic of mobile phone misuse. PUMRJ [Internet]. 4May2019 [cited 21Jul.2021];2(1):22-6. Available from: https://www.praxisug.com/index.php/Praxis/article/view/55 http://nbn-praxis.de/ urn:nbn:de:praxis-praxis.v2i1.555

30. Noyan, C. O., Darçin, A. E., Nurmedov, S., Yilmaz, O., \& Dilbaz, N. (2015). Validity and reliability of the Turkish version of the Smartphone Addiction Scale-Short Version among university students. Anadolu Psikiyatri Dergisi, 16, 73

31. Kwon, M., Kim, D. J., Cho, H., \& Yang, S. (2013). The smartphone addiction scale: development and validation of a short version for adolescents. PloS one, 8(12), e83558. https://doi. org/10.1371/journal.pone.0083558

32. Ağargün, M. Y., Kara, H., \& Anlar, O. (1996). The validity and reliability of the Pittsburgh sleep quality index. Türk Psikiyatri Dergisi, 7(2), 107-115.

33. Haug, S., Castro, R. P., Kwon, M., Filler, A., Kowatsch, T., \& Schaub, M. P. (2015). Smartphone use and smartphone addiction among young people in Switzerland. Journal of behavioral addictions, 4(4), 299-307. https://doi.org/10.1556/2006.4.2015.037 34. Bulduklu, Y., \& Özer, N. P. (2016). Gençlerin Akıllı Telefon Kullanım Motivasyonlar1. Itobiad: Journal of the Human \& Social Science Researches, 5(8).

35. Kocamaz, D., Badat, T., Maden, T., \& Tuncer, A. (2020). The Relationship of Smartphone Use with Sleep Quality and Depression in University Students. Journal Of Exercise Therapy And Rehabilitation, 7(3), 253-259.

36. Sohn, S., Rees, P., Wildridge, B., Kalk, N. J., \& Carter, B. (2019). Prevalence of problematic smartphone usage and associated mental health outcomes amongst children and young people: a systematic review, meta-analysis and GRADE of the evidence. BMC psychiatry, 19(1), 1-10. . https://doi.org/10.1186/ s12888-019-2350-x

37. Yumuşak M. The Effects of Smartphone Addiction on the Levels of Sleep Quality and Life Satisfaction in University 
Students. Master Thesis, 2019 Erciyes University Health Sciences Institute, Department of Nursing.

38. Chung, J. E., Choi, S. A., Kim, K. T., Yee, J., Kim, J. H., Seong, J. W., . \& Gwak, H. S. (2018). Smartphone addiction risk and daytime sleepiness in Korean adolescents. Journal of paediatrics and child health, 54(7), 800-806. https://doi.org/10.1111/ jpc. 13901

39. Özcan B. Sleep Quality in Pamukkale University Students and Its Relationship with Smartphone Addiction. Master Thesis, Pamukkale University Faculty of Medicine, Department of Public Health İstanbul, 2019.

40. Yıldırım, S., Kolcu, G., Başaran, Ö., \& Tamam, İ. (2019). Smartphone Addiction and Associated Factors in First Year Medical Faculty Students of a University.Sdü Tip Fakültesi Dergisi, 26(4), 396-407. https://doi.org/10.17343/sdutfd.481035 41. Kuyucu, M. (2017). The problem of smartphone use and smartphone addiction among young people: "Smartphone (colic)" university youth.Global Media Journal TR Edition, 7(14), 328-359. 42. Öcal Üstündag N. The Risk of Smartphone Addiction, Its Effect on Sleep Quality, and Its Relationship with Mental Symptoms in University Students. PhD Thesis, 2019 Erciyes University Institute of Health Sciences, Department of Public Health.

43. Keskin, T., Ergan, M., Başkurt, F., \& Başkurt, Z. (2018). The Relationship between Smartphone Use and Headache in University
Students. Adiyaman University Journal of Health Sciences,4(2), 864-873. https://doi.org/10.30569/adiyamansaglik.428223

44. Erdoğanoğlu, Y., \& Arslan, B. C.. (2019). The effect of smartphone use on physical capacity in young people. Anatolian Journal of Psychiatry/Anadolu Psikiyatri Dergisi, 20(5). http:// dx.doi.org/10.5455/apd.22386

45. Ozkaya, H., Serdar, M., Acar, H., Pekgor, S., \& Arica, S. G. (2020). Evaluation of the frequency/addiction of smartphone use and its effect on sleep quality in university students. Annals of Medical Research, 27(2), 657-663. Doi: 10.5455/ annalsmedres.2019.11.737

46. Çevik C. Investigation of the Relationship between Smartphone Addiction and Sleep Quality, Depression and Anxiety Levels in University Students. Master Thesis, Üsküdar University Institute of Social Sciences, Department of Clinical Psychology,İstanbul, 2018

47. Haripriya, S., Samuel, S. E., \& Megha, M. (2019). Correlation Between Smartphone Addiction, Sleep Quality And Physical Activity Among Young Adults. Journal OfClinical \& Diagnostic Research, 13(10).

48. Sohn, S. Y., Krasnoff, L., Rees, P., Kalk, N. J., \& Carter, B. (2021). The association between smartphone addiction and sleep: a UK cross-sectional study of young adults. Frontiers in psychiatry, 12. Doi: https://dx.doi.org/10.3389\%2Ffpsyt.2021.629407 